\title{
Urgent Application of Extracorporeal Membrane Oxygenation in Amniotic Fluid Embolism
}

\author{
Moo Suk Park, M.D. \\ Division of Pulmonology and Critical Care Medicine, Department of Internal Medicine, Severance Hospital, Institute of Chest Diseases, Yonsei University College of Medicine, Seoul, \\ Korea
}

Since 1972, veno-veno (VV) extracorporeal membrane oxygenation (ECMO) has been used as life-saving therapy in adults with ARDS and refractory hypoxia,[1] and veno-arterial (VA) ECMO has been used to treat cardiogenic shock. At present, ECMO is a lifesaving therapeutic consideration and is widely used for management of patients with severe hypoxemia or cardiogenic shock for recovery and bridging to transplantation.

In specially, ECMO is used in acute massive pulmonary embolism. In a systemic review, ECMO was used in the majority of cases, as it allows rapid correction of abnormal physiology, preventing severe organ failure by providing cardiorespiratory support until clot dissolution with systemic heparinization.[2] ECMO for selected patients with massive PE is associated with good outcomes. ECMO use in the context of massive pulmonary embolism (PE) should be considered, balancing purported benefits and likelihood of recovery without significant neurological sequelae and potential risks.[2]

In this topic of The Korean Journal of Critical Care Medicine, Lee et al.[3] reported a case titled "Use of Extracorporeal Membrane Oxygenation in Fulminant Course of Amniotic Fluid Embolism Syndrome Immediately after Cesarean Delivery."

Amniotic fluid embolism (AFE) is a rare but potentially fatal complication that occurs acutely during pregnancy or within $12 \mathrm{~h}$ of delivery. AFE is highly suspected in the pregnant or postpartum patient who presents with acute hemorrhage with disseminated intravascular coagulation (DIC), altered mental status, hypotension, or respiratory distress. Differential diagnoses such as pulmonary embolism, sepsis, anaphylaxis, and myocardial infarction must be excluded.[4]

The authors showed a case of a 36-year-old woman with clinical AFE who developed severe hypoxemia and circulatory collapse and was treated successfully with the application of VA ECMO but who suffered from impaired cognitive function. They suggested that urgent ECMO should be considered when amniotic fluid

\author{
Moo Suk Park \\ Division of Pulmonology and Critical \\ Care Medicine, Department of Internal \\ Medicine, Severance Hospital, Institute \\ of Chest Diseases, Yonsei University \\ College of Medicine, 50-1 Yonsei-ro, \\ Seodaemun-gu, Seoul 03722, Korea \\ Tel: +82-2-2228-1955 \\ Fax: +82-2-393-6884 \\ E-mail: pms70@yuhs.ac \\ ORCID \\ Moo Suk Park \\ http://orcid. org/0000-0003-0820-7615 \\ *No potential conflict of interest relevant to this \\ article was reported.
}


embolism syndrome is suspected in patients presenting acute cardiopulmonary collapse, such as in this case.

Recently, another similar case reported that VV ECMO was applied because of sudden acute respiratory failure combined with DIC, but not combined with circulatory collapse or altered mental status.[5] The patient in that report demonstrated no impaired cognitive function.

Taken together, these findings indicate that ECMO is a lifesaving and effective therapeutic consideration for management of patients with AFE and should be applied as early as possible.

\section{References}

1) Hill JD, O'Brien TG, Murray JJ, Dontiqny L, Bramson ML, Osborn JJ, et al: Prolonged extracorporeal oxygenation for acute post-traumatic respi- ratory failure (shock-lung syndrome). Use of the Bramson membrane lung. N Engl J Med 1972; 286: 629-34.

2) Yusuff HO, Zochios V, Vuylsteke A: Extracorporeal membrane oxygenation in acute massive pulmonary embolism: a systematic review. Perfusion 2015; 30: 611-6.

3) Lee JH, Jan HJ, Park JH, Kim YK, Min HK, Kim SY, et al: Use of extracorporeal membrane oxygenation in a fulminant course of amniotic fluid embolism syndrome immediately after cesarean delivery. Korean J Crit Care Med 2016; 31: 256-61.

4) Clark SL: Amniotic fluid embolism. Obstet Gynecol 2014; 123(2 Pt 1): 337-48.

5) Kang HS, Lee HY, Lee HY, Kim SC: Successful application of extracorporeal membrane oxygenation for a patient with clinical amniotic fluid embolism. Korean J Crit Care Med 2015; 30: 303-7. 